\title{
Assessment of Foveal Cone Photoreceptors in Stargardt's Macular Dystrophy Using a Small Dot Detection Task
}

\author{
ANDREW M. GELLER, ${ }^{*} \dagger$ PAUL A. SIEVING $\ddagger$ \\ Received 7 May 1992; in revised form 15 December 1992
}

\begin{abstract}
We measured frequency-of-seeing curves for tiny (1.125 and $3.375 \mathrm{~min}$ arc) stimuli flashed briefly at absolute threshold to estimate the density of foveal cones in normals and in subjects with Stargardt's macular dystrophy. Foveal absolute thresholds for Stargardt's were elevated 1.5 log units over normal. Analysis using Poisson counting statistics indicated that the quantal absorption to stimulate individual cones was normal for Stargardt's but that effective optical density of individual cones was reduced by $>1 \log$. Numerical density of foveal cones was reduced $1 \log$ unit for Stargardt's patients with acuities of 20/30-20/100.
\end{abstract}

Psychophysics Cone Stargardt's Human Fovea Absolute threshold Optical density Retina

\section{INTRODUCTION}

Stargardt's disease is an autosomal recessive macular dystrophy, characterized by macular retinal pigment epithelium (RPE) atrophy, the deposition of lipofuscin in the RPE, particularly in the variation called fundus flavimaculatis, and reduced central vision, typically by the first or second decade of life, although some do not report diminished vision until their fourth or fifth decade (Noble \& Carr, 1979; Fishman, Farber, Patel \& Derlacki, 1987; Weleber \& Eisner, 1988; Bird \& Marshall, 1982; Noble \& Carr, 1979). The macular RPE progressively becomes atrophic, and the fundus fluorescein angiogram typically shows a hyperfluorescent "window defect" in the atrophic area. Although some investigators differentiate between Stargardt's and fundus favimaculatis by fundus appearance, visual acuity is diminished in both once the fovea is involved. Loss of acuity does not correlate well with the appearance of the macula, particularly in early stages (Noble \& Carr, 1979). Peripheral retinal function is typically minimally affected, and these patients maintain normal visual fields and normal electroretinogram (ERG) rod and cone responses on full-field testing.

Our interest was to take a census of the foveal cone photoreceptor population in subjects with Stargardt's. Foveal densitometry indicates that foveal cone optical

*Department of Psychology, W. K. Kellogg Eye Center, University of Michigan, 1000, Wall Street, Ann Arbor, MI 48105, U.S.A

†Present address: Center for Environmental Medicine and Lung Biology, University of North Carolina at Chapel Hill, Chapel Hill, NC 27599, U.S.A.

‡Department of Ophthalmology, W. K. Kellogg Eye Center, University of Michigan, 1000, Wall Street, Ann Arbor, MI 48105, U.S.A. density (OD) is reduced in this pathology, although it cannot differentiate between reduction due to a change in actual OD or a decrease of photoreceptor number (van Meel \& van Norren, 1986). Different levels of photoreceptor loss have been reported in different histopathological samples (Eagle, Lucier, Bernardino \& Yanoff, 1980; Klien \& Krill, 1967). In a histopathological study of the eye of one young patient with this juvenile macular degeneration, the RPE was reported to be absent from the fovea and most of the photoreceptors were missing, yet this patient maintained 20/30 acuity just prior to his accidental death (Eagle et al., 1980). Thus a disparity remains between the anatomical and psychophysical data.

In a previous paper (Gellcr, Sicving \& Grecn, 1992), we discussed the ineffectiveness of using globally redundant stimuli like gratings to estimate the density of the photoreceptor population based on sampling considerations. We found that grating orientation could be identified correctly under conditions that simulated massive loss of receptors. Consequently, it seemed that this approach would not be fruitful for studying these subjects. This conclusion had been foreshadowed by studies of amblyopia (Wilson, 1991) and of foveal aliasing which showed that undersampled stimuli can be identified under certain conditions (Williams \& Coletta, 1987; Williams, 1990)

In contrast to globally redundant gratings, we have now used discrete tiny spot stimuli to quantify the photoreceptor population, based on the work of $\mathrm{Ci}$ cerone and Nerger $(1989 a, b)$, who modeled the frequency-of-seeing curves of normal and dichromatic observers tested with tiny (1-3 min arc dia) stimuli to obtain estimates of both the relative and absolute 
TABLE 1. Characteristics of observers with Stargardt's macular dystrophy

\begin{tabular}{|c|c|c|c|c|c|c|}
\hline Name & Age & $\begin{array}{l}\text { Visual } \\
\text { acuity }\end{array}$ & $\begin{array}{l}\text { Fundus } \\
\text { (macula) }\end{array}$ & $\begin{array}{l}\text { Full field rod } \\
\text { and cone ERG }\end{array}$ & $\begin{array}{l}\text { Rod dark } \\
\text { adapted } \\
\text { thresholds }\end{array}$ & $\begin{array}{c}\text { Visual } \\
\text { fields } \\
\text { (Goldmann } \\
\text { V4e and 14e) }\end{array}$ \\
\hline AW & 19 & $20 / 30$ & $\begin{array}{l}\text { Foveal and } \\
\text { parafoveal flecks, } \\
\text { macular RPE } \\
\text { granularity }\end{array}$ & Normal & Normal & Full \\
\hline $\mathrm{AP}$ & 20 & $20 / 70$ & $\begin{array}{l}\text { Foveal RPE atrophy, } \\
\text { RPE granularity, } \\
\text { parafoveal flecks }\end{array}$ & Normal & Normal & Full \\
\hline RM & 51 & $20 / 70$ & $\begin{array}{l}\text { Foveal RPE atrophy, } \\
\text { parafoveal flecks }\end{array}$ & Normal & Normal & Full \\
\hline BS & 29 & $20 / 100$ & $\begin{array}{l}\text { Foveal RPE atrophy, } \\
\text { RPE granularity, } \\
\text { parafoveal flecks }\end{array}$ & $\begin{array}{l}\text { Normal cone } \\
\text { subnormal } \\
\text { rod amplitude }\end{array}$ & Normal & Ful] \\
\hline BH & 22 & $20 / 100$ & $\begin{array}{l}\text { Parafoveal flecks, } \\
\text { macular RPE } \\
\text { granularity }\end{array}$ & Normal & Normal & Full \\
\hline RPB & 39 & $<20 / 200$ & $\begin{array}{l}\text { Parafovcal flecks, } \\
\text { foveal RPE atrophy }\end{array}$ & Normal & Normal & Full \\
\hline $\mathbf{K H}$ & 29 & $<20 / 200$ & $\begin{array}{l}\text { Foveal RPE atrophy, } \\
\text { macular RPE } \\
\text { granularity }\end{array}$ & Normal & Normal & Full \\
\hline
\end{tabular}

numbers of middle- and long-wavelength-sensitive cones in the fovea. We have also incorporated elements of the model of foveal detection presented by Vimal, Smith, Pokorny and Shevell (1989) to evaluate and model photoreceptor function and numbers in patients with Stargardt's macular degeneration.

We measured frequency-of-seeing functions at absolute foveal threshold with small dot stimuli and modeled these data to estimate the number of receptors illuminated by the test field, the quantal requisite for activation of a cone, and the effective quantal absorption by the photoreceptors. In the normal population, estimates of photoreceptor number and quantal activation corresponded to those expected from the known anatomy and from previous work. The Stargardt's patients showed foveal thresholds elevated by approx. $1.5 \log$ units over the normals and the frequency-of-seeing functions had reduced slope. For these patients, we were able to exclude models which hold that photoreceptor loss or a change in the quantal requisite for activation as exclusively responsible for these differences. A model that combined both of photoreceptor loss plus a change in quantal absorption due to reduced optical density best accounted for the changes in detection seen in the Stargardt's patients.

\section{METHODS}

\section{Observers}

Informed consent was obtained from all participants. $1 \%$ Mydriacyl (tropicamide) was used to dilate the pupil and relax accommodation. The left eye was tested in all observers.

Eleven normal observers were tested, eight male and three female, age 21-38 yr old. Four had previous experience as subjects in psychophysical experiments. All normals had visual acuity correctable to Snellen 20/20 and had normal color vision on the Farnsworth-Munsell Dictotomous (D-15) test.

Seven observers with Stargardt's macular dystrophy, six female and one male, were also tested (Table 1). Five of the seven Stargardt's observers had only minor crossing errors on D-15 testing, while one subject with a consistent major crossing error performed consistent with a protan defect, as described previously for Stargardt's (Birch, Chisholm, Kinnear, Marré, Pinckers, Pokorny, Smith \& Verriest, 1979).

Rayleigh match midpoint and range were measured on a Nagel anomaloscope model I (Schmidt \& Haensch). Range was established by requiring the observer to make matches of both color and brightness against the reference hemifield to various mixtures of the long and middle wavelength primaries set by the experimenter. Match midpoint was taken as the midpoint of each subject's range settings. No difference was found between the Rayleigh match midpoints of patients and normal observers. However, the range of the Stargardt's observers was broadened considerably and five of six patients who could perform this task showed the protanomalous pattern of matches characteristic of Stargardt's (Birch et al., 1979; Pokorny, Smith \& Ennest, 1980).

No central scotoma were uncovered in the patients by testing with the $\mathrm{I}-4 \mathrm{E}$ probe $\left(0.25 \mathrm{~mm}^{2}\right.$, bright spot $)$ of the Goldmann perimeter.

\section{Apparatus}

Stimuli were presented through a three-channel Maxwellian view optical system, which allowed for the independent presentation of the test field and fixation targets as well as a background field when necessary (Fig. 1). The image size at the pupil was $2.5 \mathrm{~mm}$. 
3-Channel Maxwellian View Optical System

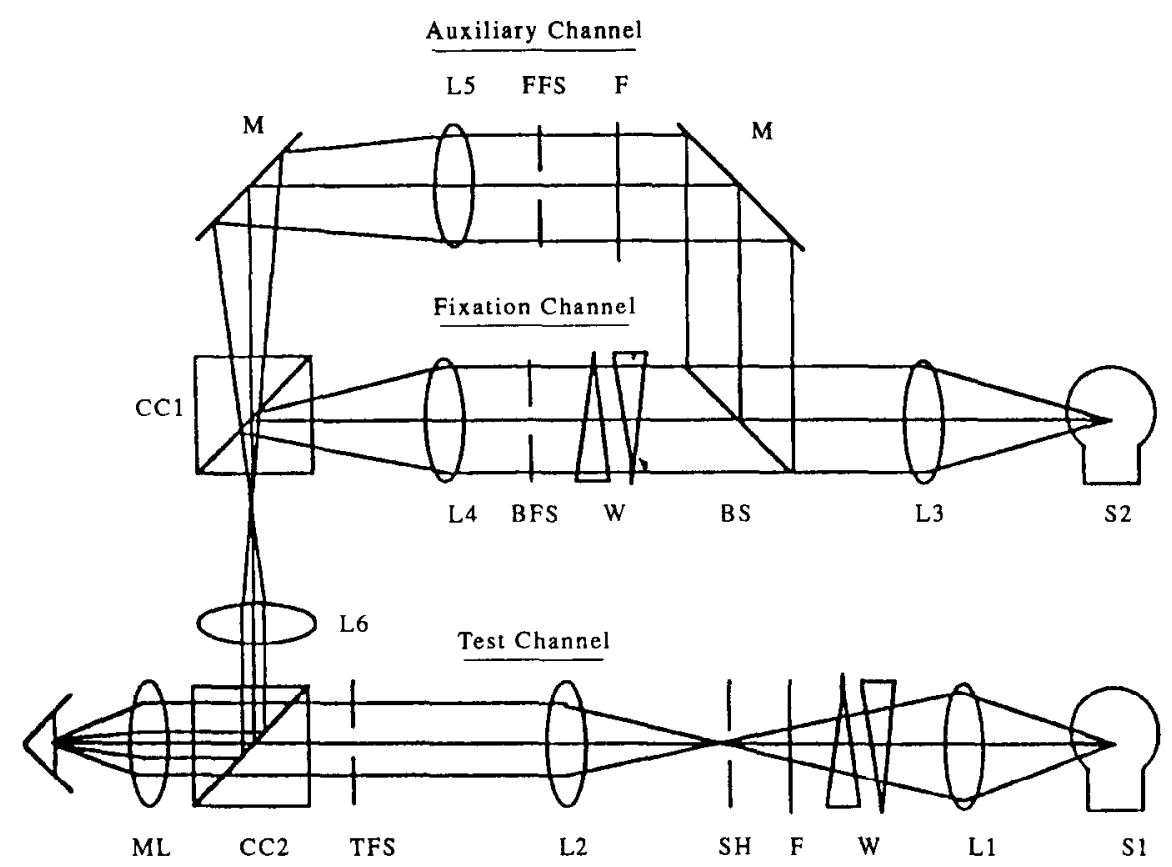

FIGURE 1. Psychophysical apparatus. Test channel: light from source $\mathrm{Sl}$ is focused by lens $\mathrm{LI}$ in the plane of shutter SH and is recollimated by lens L2 before passing through the pinhole aperture TFS (test field stop). It is brought to a focus in the plane of the observer's pupil by Maxwellian lens ML. Cube CC2 combines test and fixation. The image of the rectangular lamp filament is approx. $2.5 \mathrm{~mm}$ in length. TFS is conjugate to the observer's retina. Light is attenuated by circular neutral density wedges $\mathrm{W}$ in balanced pair. Interference and neutral density filters are positioned at $\mathrm{F}$. A silent shutter for catch trials in the method of constant stimuli was also placed at position SH. Auxiliary and fixation channels: light from source S2 is collimated by lens L3, split by half-silvered mirror BS and then passes either through field stop FFS or field stop BFS, which are both conjugate with the observer's retina. The light is converged by lenses L4 and LS and recombined with the test channel by nirror $\mathrm{M}$ and a combining cube $\mathrm{CCl}$ before being focused in the plane of the pupil.

Calibrated $25 \mu$ and $75 \mu$ pinholes (Melles Griot) were used to create test fields of geometric image diameter 1.125 and $3.375 \mathrm{~min}$ arc. The pinhole was positioned to compensate for spherical correction of the observer without changing the test field size, in accordance with the Badal principle (Ogle, 1971).

The test field and fixation targets were both conjugate with the observer's retina and centered on the fovea. Since one might assume that Stargardt's patients have subtle central scotoma, we designed fixation to circumvent this problem. The fixation target was a pattern of small spots dimly illuminated with "white" light to a just visible state for each patient and normal subject. The spots were arranged at the corners of three concentric squares, with the innermost spots located $0.75 \mathrm{deg}$ from the test field center, the outermost at $1.5 \mathrm{deg}$. Observers were aligned to the Maxwcllian ficlds by viewing large concentric circular fields placed in both test and fixation channels and positioning themselves so that one field was centered in the other and both were of maximal perceived brightness. During this process, the experimenter checked that the beam entered the center of the pupil. Because the filament image from the fixation channel was on the order of 2.5 times the size of the test at the pupil, small deviations from the aligned position resulted in partial occlusion of the fixation beam by the edge of the pupil, dimming the already "just visible" fixation spots. To keep the fixation spots visible, observ- ers had to maintain foveal fixation. Position was held for the duration of the experiment with a dental impression bite-bar.

Stimulus presentation and data collection were computer-controlled through a PC-XT computer to which the observer communicated responses using a four-button switch box. The shutter (Vincent Uniblitz) had rise and fall times of $1.5 \mathrm{msec}$ at half-height and responded to computer logic signals for timed exposure duration and inter-stimulus interval.

Wavelength was controlled with a $580 \mathrm{~nm}$ three-cavity interference filter (Melles Griot, calibration curve shows $10 \mathrm{~nm}$ width at half-height) to stimulate both long- and middle-wavelength-sensitive cones. This wavelength was selected after performing pilot color-naming experiments as described in Cicerone and Nerger (1989a).

The test source luminance was calibrated at the completion of each experimental session using a spectrallycalibrated UDT PIN-10 detector or a calibrated UDT $40 \times$ Optometer (United Detector Technologies).

\section{Procedure}

Observers were dark-adapted for $10 \mathrm{~min}$, and initial determinations of absolute threshold were made using a modified staircase procedure beginning at intensities below each observer's detection threshold. The observer fixated the center of the fixation target and the test field was flashed for $20 \mathrm{msec}$ once every $3 \mathrm{sec}$, accompanied 
by the audible click of the shutter. The observer judged whether or not $\mathrm{s} /$ he saw the flash. If the test was not visible, the observer repetitively incremented the intensity by $0.03 \mathrm{log}$ unit steps until the test flash was just visible, and then decremented intensity until the flash just disappeared. For each run, the threshold estimate was the mean of three "just visible" and three "just disappeared" settings. Runs were repeated until three estimates of threshold were within $0.1 \log$ units, and the mean value was determined.

This mean estimate of cone threshold became the midpoint of eleven test intensities over $0.93 \log$ units at even steps of $0.093 \mathrm{log}$. Data were collected by the method of constant stimuli in which the subject was asked to respond "yes" or "no" to whether s/he saw each test flash. The observer pressed a trigger button to present the test flash for $20 \mathrm{msec}$ with a minimum inter-stimulus interval of $3 \mathrm{sec}$. Each experimental session consisted of 242 flashes presented in random intensity order, with approx. 20 at each intensity plus $10 \%$ catch trials, for which the shutter clicked audibly but no flash was presented. The observer rested as needed.

The $20 \mathrm{msec}$ exposures were chosen to be within the temporal integration period of cone photoreceptors (Baumgardt, 1972; Boynton, 1972; Hood \& Finkelstein, 1988 ), since quanta presented outside this window would not necessarily contribute to threshold excitation. Temporal summation characteristics of two normal observers were determined under our standard observation conditions for flash durations of $8-50 \mathrm{msec}$ with a test field of $1.125 \mathrm{~min}$ diameter. The duration of $20 \mathrm{msec}$ was within the range of the linear intensity-time trade-off for both observers.

\section{Analysis and modeling}

The data were corrected for false alarms using Abbott's correction (Green \& Swets, 1966). Corrected $P($ yes $\mid x)$ values $<0$ were not included in any of the parameter estimation. False alarm rates were very low or zero.

Data were fit with the equation from Cicerone and Nerger $(1989 a, b)$

$$
P(\text { yes } \mid x)=1-\Pi(x)^{N}
$$

in which $P(y e s \mid x)$ is the probability of saying "yes" to a flash of average intensity $x . \Pi(x)$ is the probability that an individual photoreceptor did not signal the flash, and $\Pi(x)^{N}$ is the cumulative probability that none of $N$ detectors illuminated by the test flash were activated, i.e. that the subject responded with a "no". This assumes that the foveal cones each act as multiple dependent detectors (cf. Green, 1970; Thibos, Cheney \& Walsh, 1987; Wässle, Grünert, Röhrenbeck \& Boycott, 1989; DeMonasterio \& Gouras, 1975; Derrington \& Lennie, 1984 ) and that the activation of a single cone would be sufficient to give rise to vision (Krauskopf \& Srebo, 1965; Krauskopf, 1978).
The probability of not activating an illuminated photoreceptor was

$$
\Pi(x)=\sum_{k=0}^{m-1}\left(\mathrm{e}^{\mathrm{x} x} x^{k} / k !\right)
$$

the Poisson probability that no illuminated detector absorbed the requisite number of quanta $(m)$ to be activated by a flash of average intensity $(x)$ "effective quanta"/detector. Effective quanta are those which are absorbed and isomerize photopigment (Pirenne \& Marriott, 1959).

Although stimulus intensity is measured at the cornea, the intensity parameter $x$ must be interpreted in terms of effective quanta/detector unit. Hence, the value $x$ reflects the number of photoreceptors (i.e. $N$ ) over which the quanta are distributed on the retina. This was particularly important both in comparing data from patients and normals and in making comparisons across field sizes. For the same corneal intensity, threshold intensity was lower in terms of quanta per unit area with a larger field. Similarly, the normal observers needed far less light to make threshold detections than the patients. These differences had to be reflected in the intensity range used to fit the data, i.e. the same range of $x$ values could not be used to fit data from both large and small field sizes and from both observer populations.

In this respect, our modeling was different from that of Cicerone and Nerger $(1989 a, b)$ who used coneisolation conditions while matching the detection functions to hold the number of illuminated detectors constant when they made field size comparisons. This allowed them to estimate values for $x$ using the same relative intensity scale for all conditions. For our experiments however, as the test field size was increased, more detectors were recruited. Therefore it was necessary to calculate effective retinal illuminance in order to anchor the intensity scale $(x)$. Two approaches were used. First, estimates were obtained from the literature to account for absorption and reflection by the ocular media and photoreceptors, similar to the approach used by Hecht, Schlaer and Pirenne (1942). Second, values of $m$ were obtained from the literature, together with an approximation of $N$ from the known retinal anatomy. These were used to estimate a new parameter $n d$ which scaled the corneal intensity to the value that would reflect quanta/detector at the fovea. Estimates of $m$ and $N$ were then obtained by recursively fitting the data with equation (1) using these intensity estimates.

\section{RESULTS AND ANALYSIS}

\section{Normal observers}

Data from the normal observers are shown in Fig. 2 with best-fitting curves to differentiate individual observers. All observers needed fewer quanta per unit retinal area to detect the larger test than the smaller. For both the 1.125 and $3.375 \mathrm{~min}$ arc test conditions, there was an approx. $0.5 \log$ unit spread in threshold intensity over observers, with one notable outlier in the small test field condition. This observer was also at the maximum end 


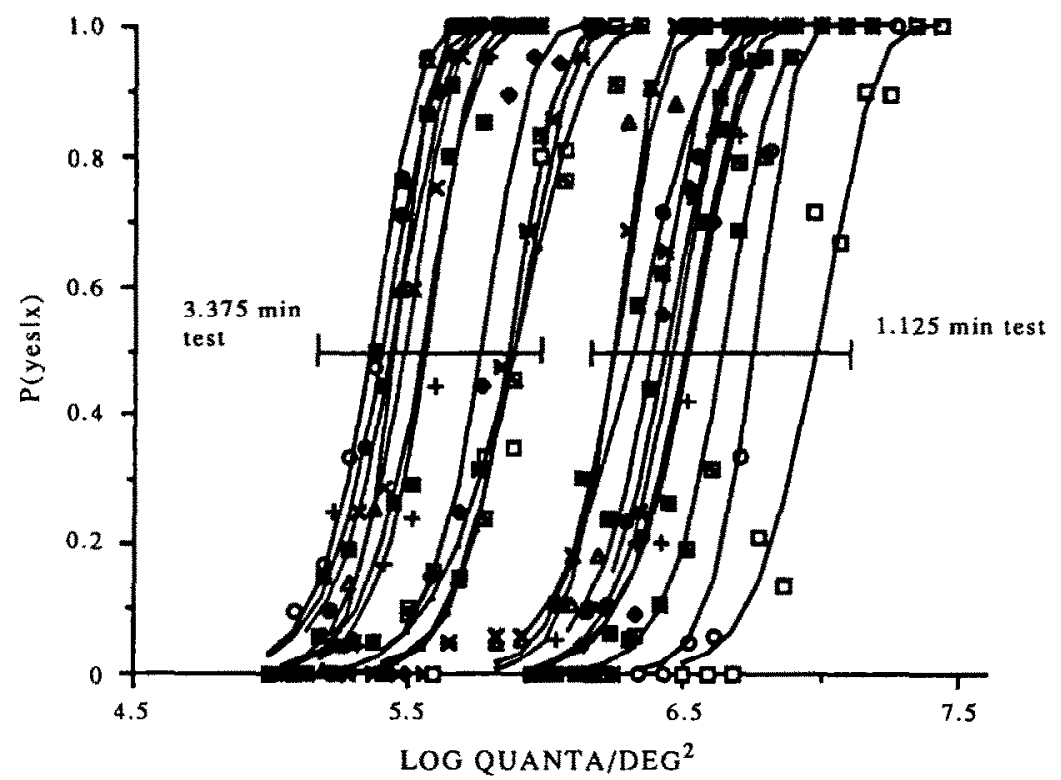

FIGURE 2. Frequency-of-seeing data for normal observers measured with $580 \mathrm{~nm}$. Square brackets at $P(y e s \mid x)=0.50$ assist in grouping the data sets. Solid curves are best fits through each individual's data.

of the intensity range in the $3.375 \mathrm{~min}$ arc condition and had a larger than normal range of matches on the Nagel anomaloscope.

The performance of those normal observers who underwent repeated testing was consistent over sessions, both in the shape of the frequency-of-seeing curves and the location along the intensity axis. There was no significant difference between the experienced psychophysical observers and the naive normal observers in the thresholds or the shapes of their frequency-of-seeing functions.

Approach 1 -determination of $m$ and $N$ by estimating retinal illumination and absorption. To use the Cicerone and Nerger model to estimate photoreceptor numbers $N$ and the quantal requisite $m$, the number of effective quanta/photoreceptor at absolute threshold was estimated, beginning with corneal intensity, using losses to the media (Table 2), and incorporating the foveal cone absorptance and quantum efficiency of bleaching at $580 \mathrm{~nm}$ to account for photoreceptor factors (Table 2). This yielded the estimate that approx. $27 \%$ of the quanta incident on the cornea would result in isomerization of photopigment in foveal cones.

The quantal intensity per photoreceptor unit area was estimated based on a calculation of retinal image size according to optical considerations (Gubisch, 1967) and the anatomical size of human foveal cone photoreceptors (Hirsch \& Curcio, 1989). The retinal light distribution for tiny stimuli is calculated by convolving the object with the linespread function of the eye (Westheimer, 1986; Gubisch, 1967). This was done in the frequency domain, multiplying the Fourier frequency transform of the object $F(w)$ by the Fourier transform of the linespread $T(w)$ (i.e. the modulation transfer

TABLE 2. Transmission and absorbance factors for foveal vision

\begin{tabular}{|c|c|c|}
\hline $\begin{array}{l}\text { Proportion } \\
\text { of incident } \\
\text { quanta } \\
\text { transmitted }\end{array}$ & $\begin{array}{l}\text { Optical factors and } \\
\text { ocular media }\end{array}$ & Reference \\
\hline 0.96 & Corneal reflection & Wyszecki and Stiles (1982) \\
\hline 0,90 & Corneal transmission & Wyszecki and Stiles (1982) \\
\hline 0.912 & $\begin{array}{l}\text { Transmitted by lens and } \\
\text { macular pigment @ } 580 \mathrm{~nm}\end{array}$ & Wyszecki and Stiles (1982) \\
\hline 0.80 & Transmitted by vitreous & Wyszecki and Stiles (1982) \\
\hline \multicolumn{3}{|c|}{ Absorbance factors } \\
\hline 0.7015 & Absorptance $=1-10^{-0.523}$ & Bowmaker (1981) \\
\hline 0.70 & $\begin{array}{l}\text { Quantum efficiency of } \\
\text { bleaching }\end{array}$ & Fein and Szuts (1982) \\
\hline 0.87 & $\mathrm{~V}(\lambda), \lambda=580 \mathrm{~nm}$ & Wyszecki and Stiles (1982) \\
\hline \multicolumn{3}{|l|}{ Total } \\
\hline 0.269 & $\begin{array}{l}\text { Proportion of light incident at } \\
\text { cornea which isomerizes cone } \\
\text { pigment }\end{array}$ & \\
\hline
\end{tabular}




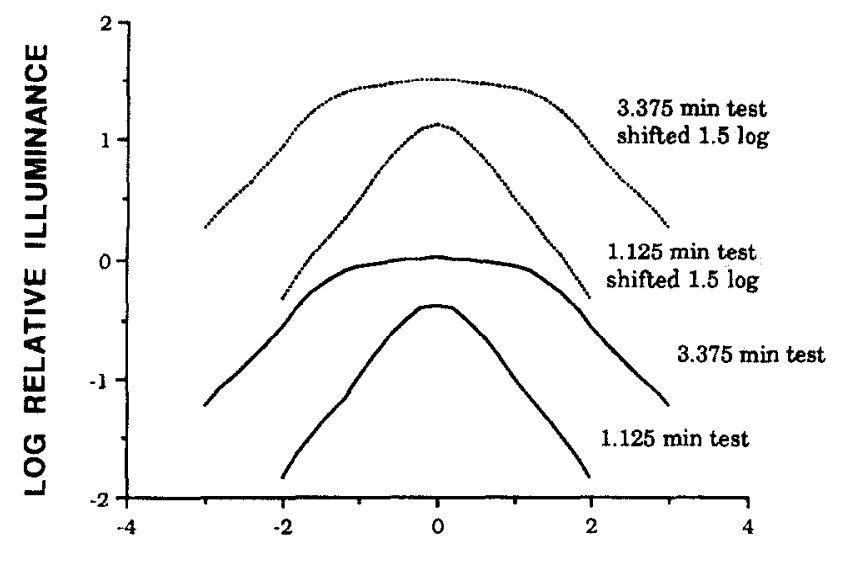

DISTANCE FAOM CENTER (MIN OF ARC)

FIGURE 3. Retinal illuminance profiles for 1.125 and $3.375 \mathrm{~min}$ arc diameter test fields. Relative position of curves along abscissa indicates relative peak illuminances. Dotted curves show illuminance profiles shifted $1.5 \mathrm{log}$ brighter to represent viewing conditions of Stargardt's observers.

function) for an eye with pupil size equal to $2.4 \mathrm{~mm}$ (Campbell \& Gubisch, 1966), approximately equivalent to our viewing conditions. The inverse Fourier transform gives the retinal image profile shown in Fig. 3 (Gubisch, 1967).

With regard to the light distribution, one must distinguish between physical properties and physiological effects. Small stimuli must be specified in both terms, since significant energy is distributed beyond the geometric edges of the retinal images. For a normal retina, the physiologically effective diameter of the retinal light distribution was specified as the diameter at half-height, following the logic of Vimal et al. (1989), who reasoned that if a cone needs to absorb 5 quanta to be activated, then the probability that one-half the quantal flux would activate a cone is $P=(0.50)^{5}=0.03$ and thus is very unlikely. Using this half-height criterion, the small test field had a retinal image of diameter $1.3 \mathrm{~min}$ arc $(25 \mu$ field stop), while the larger test had a $3.3 \mathrm{~min}$ arc diameter ( $75 \mu$ field stop). The effective diameter for a diseased retina would change depending on the mechanism of the pathology, as is discussed below.

A further consequence of retinal image blur from optical spread is that the smaller disk had a lower peak image illuminance (Gubisch, 1967). * For the $1.3 \mathrm{~min}$ arc test field, the attenuation from peak amplitude is $-0.484 \mathrm{log}$; for the $3.3 \mathrm{~min}$ arc test, attenuation was $-0.097 \mathrm{log}$. These estimates of field size and peak attenuation yielded total physiologically effective quanta

*The formula given by Gubisch (1967) only allows one to calculate the normalized intensity profiles of the retinal image. To obtain a measure of the attenuation of the image illuminance due to its spread, one must multiply $F(w)$ by $2 \pi b^{2}$, where $b$ is the radius of the geometric image of the disk. This gives the non-normalized frequency spectrum of the disk (Hecht \& Zajac, 1979).

$\uparrow$ We can obtain non-integer values for $m$ with our fitting algorithm. SYSTAT (Wilkinson, 1989) uses the gamma cumulative function to evaluate the cumulative Poisson probabilities and can therefore treat the summation parameter $m$ as a real number. at threshold. Finally, foveal cone diameter of $0.52 \mathrm{~min}$ arc (Hirsch \& Curcio, 1989) was used to calculate the number of quanta actually effective for cone stimulation. i.e. effective quanta/cone. From these estimates, 6.33 cones were illuminated by our small field and approx. 41 by the large.

For the $3.3 \mathrm{~min}$ arc test field, $P($ yes $\mid x)=0.50$ threshold came to a median $=4.41$ effective quanta/cone (mean $=5.65$ quanta with $95 \%$ confidence limits 3.79 and 7.47) for our 11 normal observers (Table 3, column 9 ). For the smaller test field, the estimated number of quanta/cone at threshold was a median $=11.57$ $($ mean $=19.07$ with $95 \%$ confidence limits 11.19 and 26.95) (Table 3, column 5). Threshold in the small test condition was higher than in the larger test field condition ostensibly because of less favorable statistics due to the smaller number of illuminated receptors (Pirenne \& Marriott, 1955).

Once the quantal intensities at the retina per unit photoreceptor area [i.e. parameter $x$ in equation (1)] had been established, parameters $m$ and $N$ could be estimated by fitting each observer's data to equation (1) using a maximum likelihood estimator. For the $3.375 \mathrm{~min}$ arc field, the best-fitting $m$ (the number of quanta required to activate each single detector) had a median value of $m=6.63$ (mean value $m=6.83$ with $95 \%$ confidence interval $5.90-7.77,11$ normal observers) $\dagger$ The bestfitting $N$, the number of detectors illuminated, under the same conditions, had a median of $N=2.67$. (mean value $N=3.88$ with $95 \%$ confidence interval $0.407-7.349$ ).

For the $1.125 \mathrm{~min}$ arc test, the best-fitting curves had an $m$ of median value $=11.57$ (mean $=14.60,95 \%$ confidence interval 9.96-19.23, 11 normal observers) and an $N$ of median $=0.410$ (mean $=0.547,95 \%$ confidence interval $=0.277-0.817)$

The value of $m$ obtained for the larger test field corresponds well to previous estimates of 4-7 (Marriott, 1963; Cicerone \& Nerger, 1989a; Vimal et al., 1989; Wesner, Pokorny, Shevell \& Smith, 1991). The value obtained for the smaller field was higher than expected. The obtained values for $N$ were lower than the expected approx. 6 for the small test and 41 for the large.

The inconsistency of the values for $m$ and the low estimates of $N$ may reflect the uncertainty in estimating the retinal size of the test and therefore the intensity per detector. A larger image spread, for example, would disperse the light from the test over a larger region, shifting the actual range of quanta/cone to lower intensities. Another source of uncertainty is the possibility that whiles single cone activation can result in vision (Krauskopf, 1978), foveal detection could possibly involve the activation of multiple receptors (Vimal et al., 1989). There was likely also further loss of incident quanta due to effects such as scatter. Finally, some studies used lower estimates of absorptance (e.g. 20\%; Hecht et al., 1942) rather than the $70 \%$ used here (from Bowmaker, 1981).

Approach 2-determination of relative and absolute numbers of detectors by estimating an intensity attenuation factor for normal observers. This strategy was to 
TABLE 3. Normal observers: corneal thresholds, parameter $n d$, and threshold effective quanta/receptor

\begin{tabular}{|c|c|c|c|c|c|c|c|c|}
\hline Name & $\begin{array}{c}\text { Corneal } \log \\
\text { quanta at } \\
\text { threshold } \\
1.125 \text { min } \\
\text { arc test }\end{array}$ & $\begin{array}{l}n d_{1.125} \\
\times 10^{-3}\end{array}$ & $\begin{array}{l}\text { Effective } \\
\text { quanta/ } \\
\text { receptor } \\
1.125 \mathrm{~min} \\
\text { arc test }\end{array}$ & $\begin{array}{c}\text { Efrective } \\
\text { quanta/ } \\
\text { receptor } \\
1.125 \text { min arc } \\
\text { calculated } \\
\text { from Table } 2\end{array}$ & $\begin{array}{c}\text { Corneal log } \\
\text { quanta at } \\
\text { threshold } \\
3.375 \mathrm{~min} \\
\text { arc test }\end{array}$ & $\begin{array}{l}n d_{3,375} \\
\times 10^{-3}\end{array}$ & $\begin{array}{c}\text { Effective } \\
\text { quanta/ } \\
\text { receptor } \\
3.375 \\
\text { min arc test }\end{array}$ & $\begin{array}{c}\text { Effective } \\
\text { quanta/ } \\
\text { receptor } \\
3.375 \text { min arc } \\
\text { calculated } \\
\text { from Table } 2\end{array}$ \\
\hline$A G$ & 2.831 & 4.50 & 3.048 & 12.676 & 2.831 & 2.80 & 1.899 & 3.420 \\
\hline $\mathrm{JC}$ & 3.201 & 2.10 & 3.334 & 29.717 & 2.751 & 3.50 & 1.972 & 2.840 \\
\hline $\mathrm{JJ}$ & 2.681 & 6.50 & 3.119 & 8.970 & 2.841 & 6.10 & 4.227 & 3.500 \\
\hline $\mathrm{KR}$ & 2.681 & 6.50 & 3.119 & 8.970 & 2.876 & 2.58 & 1.941 & 3.790 \\
\hline LH & 3.421 & 1.20 & 3.162 & 49.320 & 3.276 & 1.014 & 1.914 & 9.530 \\
\hline $\mathrm{MJ}$ & 2.942 & 3.50 & 3.062 & 16.330 & 2.941 & 2.20 & 1.919 & 4.410 \\
\hline $\mathrm{MN}$ & 3.081 & 2.60 & 3.133 & 22.540 & 3.276 & 9.00 & 1.698 & 9.530 \\
\hline $\mathrm{RB}$ & 2.901 & 3.90 & 3.105 & 14.890 & 3.156 & 1.30 & 1.862 & 7.230 \\
\hline $\mathrm{RD}$ & 2.741 & 5.30 & 2.917 & 12.680 & 2.801 & 3.06 & 1.936 & 3.190 \\
\hline $\mathrm{KH}$ & 2.881 & 3.60 & 2.735 & 14.220 & 3.261 & 1.055 & 1.923 & 9.200 \\
\hline $\mathrm{JL}$ & 3.017 & 3.00 & 3.119 & 19.467 & 3.036 & 1.50 & 1.629 & 5.482 \\
\hline
\end{tabular}

chose an $m$ from the literature and an approximation of $N$ based on average foveal cone photoreceptor size and calculated test field diameters to construct canonicallyshaped frequency-of-seeing curves. These curves could be shifted along the intensity axis until the intensity range was found over which $\Pi(x)^{N}$ showed the same intensity dependence as the data. A new parameter nd was estimated which scaled the intensities, measured as corneal illuminance, to the retinal quanta/detector $(x)$ without affecting the shape of the curve. Thus for each individual's data, equation (4) was used

$$
P(\operatorname{yes} \mid x)=1-[\Pi(n d * X)]^{N}
$$

where $x=$ corneal intensity $(X)$ scaled by parameter $n d$. Parameters $N$ and $m$ [from equation (2)] were fixed. Parameters $n d$ subsumes all ocular, photoreceptor, and geometric factors of retinal illumination.

The value of $m=6$ was used, and $N$ was set equal to 6.33 for the small test field and to 41 for the large test field, based on the previous estimates of cone and test field sizes. The expectation was that the value of the nd intensity-scaler for the $3.375 \mathrm{~min}$ arc field would be lower than $n d$ for the $1.125 \mathrm{~min}$ arc field, consistent with probability summation, i.e. that the field with more detectors would need fewer quanta/detector. This, in fact, was found. The median estimate for $n d_{1.125}=\mathbf{0 . 0 0 3 6}$ (mean $=0.0039,95 \%$ confidence interval $0.0027-0.005$, 11 normal observers), for $n d_{3.375}=0.0022$ (mean $=$ $0.0024,95 \%$ confidence interval $0.0013-0.0034,11$ normal observers). When threshold quanta at the cornea were multiplied by these factors (Table 3 , columns $2,3,4$ and $6,7,8$ ), values were obtained for threshold effective quanta/receptor which were lower than those estimated using the screening factors in Table 2.

The process of estimating parameters $m$ and $N$ was then reiterated. Values for threshold acting quanta/ receptor (Table 3 , columns 4 and 8 ) provided refined estimates of values $x$ effective quanta/receptor; each individual's data were fit to equation (1) once again. For the $1.125 \mathrm{~min}$ arc test, this resulted in an estimate of $m$ of mean $=5.585$ with $95 \%$ confidence interval $4.96-6.21$, and an estimate of $N$ of mean $=5.864$ with $95 \%$ confidence interval 2.77-8.96, for 11 normal observers.

For the $3.375 \mathrm{~min}$ arc test, mean $m=4.89$ with $95 \%$ confidence interval $3.99-5.80$, and $N=9.82$ with $95 \%$ confidence interval 7.69-11.94, 11 normal observers. The values obtained for $m$ for the two test sizes were not significantly different, while those for $N$ were significantly different at $P<0.01$.

As cited above, the literature gives a range of values from $m=4-7$ effective quanta necessary to activate an independent foveal detector, which agrees well with the values we obtained for both test conditions.

The value of $N$, the number of detectors illuminated by the test, obtained with the $1.125 \mathrm{~min}$ arc test was in good agreement with the population mean of 6.33 cones estimated from optical considerations of the retinal field size and anatomical estimates of photoreceptor size.

The $N$ estimated from the larger test field was somewhat lower than expected from optical and anatomical considerations. One explanation may involve the estimate of the retinal image size taken as the size at half-height which may have been too conservative. Reducing this cut-off to 0.63 height $(0.20 \mathrm{log})$ would still include detectors stimulated with a $P=(0.63)^{5}=0.10$ probability of activation, which is still fairly unlikely to enable a detection event in photoreceptors at the periphery of the image. However, this seemingly small change reduces the estimated radius from $1.65 \mathrm{~min}$ arc using the half-height critcrion to $1.45 \mathrm{~min}$ arc and reduces the expected of number photoreceptors from 41 using the half-height criterion to approx. 31 with the 0.63 height cut-off. Similarly, a 0.75 criterion raises the probability of detection to only $P-0.22$ by the outermost ring of illuminated receptors while reducing the estimated radius to $1.29 \mathrm{~min}$ arc and the estimated number of photoreceptors to 25 . These relatively small changes may partially but still not fully account for the difference between the obtained and expected $N_{3.375}$. It may be that even within the tiny region spanned by the 1.125 vs $3.375 \mathrm{~min}$ arc test fields, there is a difference in the amount of summation or spatial integration of photoreceptor signals, violating our assumption of the cones 
as independent detectors, and leading to a reduced estimate of the number of detectors illuminated in the larger test condition.

In summary, for the normal observers, the estimates obtained for parameters $m$ and $N$ with the first approach were inconsistent with previous estimates and the known retinal anatomy, indicating that estimating detector illuminance using the tabulated values was not accurate enough. Using the second approach and estimating a constant ( $n d)$ to scale intensity proved to be more fruitful. This approach provided absolute estimates of $m$ which mirror those in the literature, and absolute estimates of $N$ which matched the expectations derived from calculations of retinal image size and cone photoreceptor area in the small test condition, although estimates of $N$ were somewhat lower than expected for the large test condition.

\section{The patient population}

Six individuals with Stargardt's macular dystrophy were extensively studied. Observers AW, BS, and RM could easily replicate their data (Fig. 4). Observer AP was tested under two different viewing conditions and which resulted in inter-session variability. We include
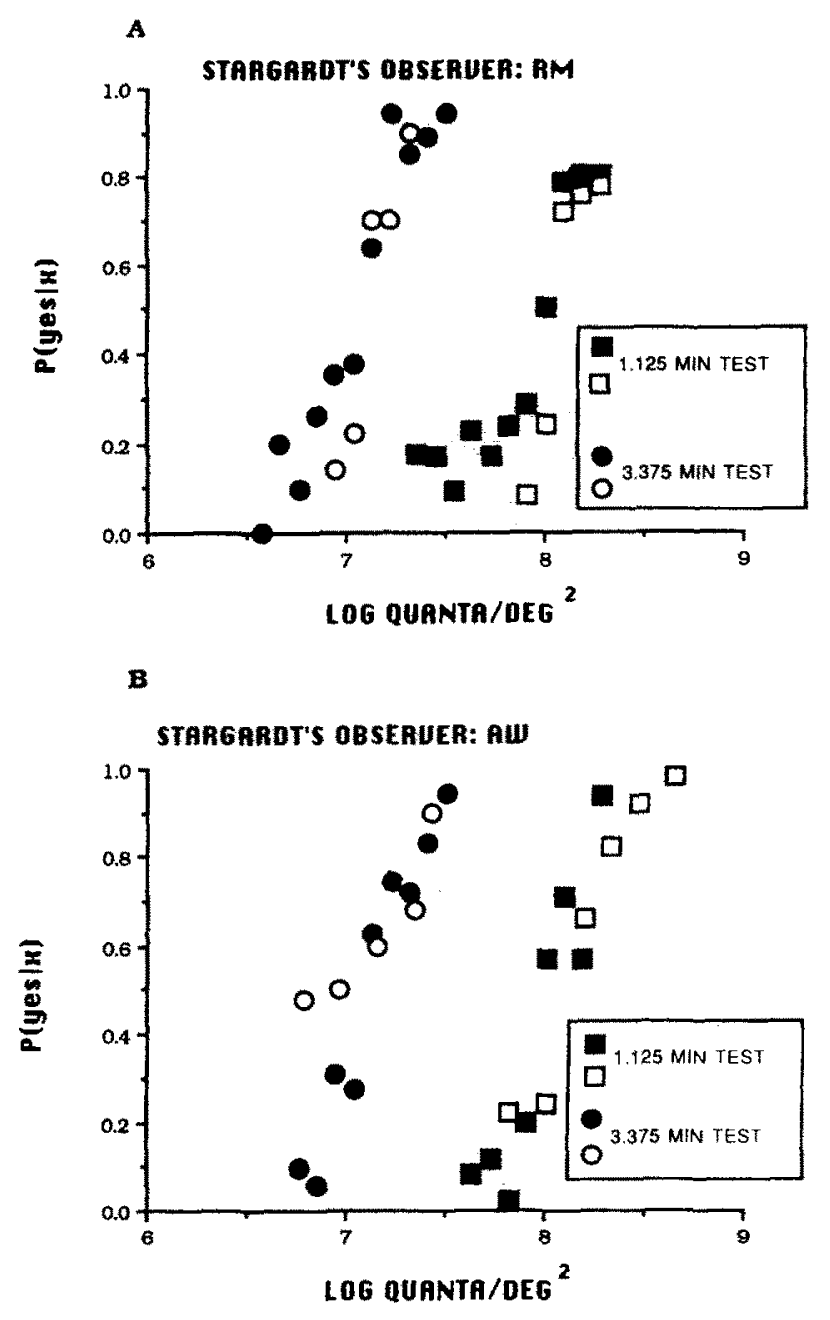

her data only from the viewing conditions shared by all other observers (Fig. 4). Two observers, RRB and KH, had extremely reduced acuity $(<20 / 200)$, and their data were not fully reliable, although their $P($ yes $\mid x)=0.50$ thresholds were elevated similarly to the other observers. Observer BH was not available for repeated testing; her data were therefore not included in population descriptions.

The most striking feature of the data from all of the patients was the elevated intensity for the frequency-ofseeing curves (Fig. 5). The modal intensity threshold of the patients was elevated on the order of $1.5 \mathrm{log}$ units over that of the normals in both 1.125 and $3.375 \mathrm{~min}$ arc viewing conditions. There was no overlap between the two populations. In addition, the slopes of the patients' frequency-of-seeing curves were shallower than for normals (Fig. 6).

\section{Analysis and modeling}

Implicit in the modeling of the normal observers' data was the assumption that there were photoreceptors illuminated on every test flash. For the patient population, however, because of the visible areas of macular atrophy as well as the histopathological evidence
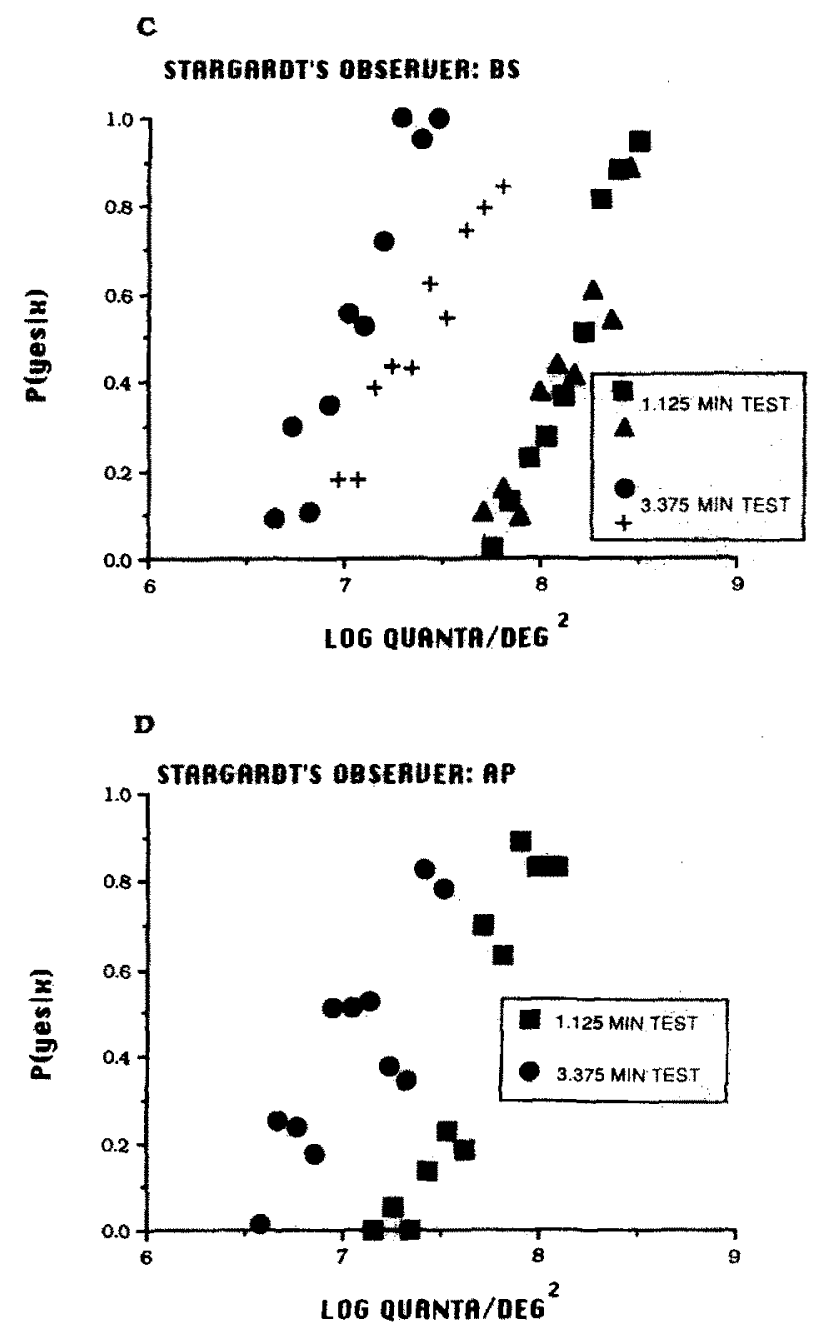

FIGURE 4. Frequency-of-seeing data from four Stargardt's patients. Solid symbols and + indicate method of constant stimuli data. Open symbols indicate data from two-alternative forced-choice procedure used in some repeated sessions. (A) Observer RM. (B) Observer AW. (C) Observer BS. (D) Observer AP. 
indicating photoreceptor losses from the fovea, we were concerned that there might be few or no photoreceptors illuminated on some test flashes. We therefore modified equation (1) to reflect the probability that quanta either did or did not hit a photoreceptor at each foveal location normally populated by a cone.

This modified equation [equation (4)] is similar to that offered by Vimal et al. (1989), who modeled long-wavelength- (LWS) and middle-wavelength-sensitive (MWS) cone simulation and introduced the notion of a "probability trough", i.e. the idea that in some locations the probability of detection is far lower than in others, leading to the construction of a duplex psychometric function. Vimal et al. (1989) conceived of a foveal mosaic constructed of locations differing in probability of detection because of the different spectral sensitivities of MWS and LWS cones. As transposed to the Stargardt's macula, this gives a mosaic in which probability of detection differed because a photoreceptor either was or was not present at each possible location. We assumed that the distribution of present and absent receptors followed a binomial sampling distribution and that the probability of activation for all receptors present was equal. The additional notation used for this model is as follows.

$S$ : "sites" illuminated, i.e. the number of spaces or positions available to be populated by foveal cones. For normal observers, $S=N$ [ $N$ from equation (1)]. $r$ : The number of photoreceptors remaining in the illuminated area. $r / S$, therefore, is the probability that a photoreceptor is present under a flash.

The second term of equation (1) therefore becomes (a) the probability that for a given density of photoreceptors, a flash will hit a photoreceptor and not activate a cone, plus (b) the probability that no cone populates a particular site and hence is not illuminated, in which case $\Pi(x)$ must approach 1 . (The probability that an unilluminated cone would fire due to thermal isomerization of the photopigment must be very low, given our assumption of multiple isomerizations for activation.) The probability of detection becomes:

$$
P(\text { yes } \mid x)=1-[r / S * \Pi(x)+(1-r / S)]^{r} .
$$

Note that when $r=S$, cquation (4) simply reduces to the form of the original equation [equation (1)], since $r=N=S$ for the fully populated normal fovea.

This model was used to examine three limiting cases for the affected retina. (1) The photoreceptor population in Stargardt's affected fovea is normal in all respects except that some cones are missing. (2) The foveal cones are all present, but the transduction mechanism is somehow altered, and required a different number of quanta for activation. (3) The foveal cones have reduced quantum-catch, such as by decreased optical density or by a change in orientation away from the pupillary axis. Intermediate combinations of effects were also considered.

Model 1--normal foveal cones but reduced number. The assumptions of this limiting condition were that both $m$ and optical density were normal but that photoreceptors had been lost. Figure 7 demonstrates the result of holding $m=5$ while assuming that only one of the normally six photoreceptors remain present. Also included are data from two patients and two normal observers from the $1.125 \mathrm{~min}$ are test condition for comparison to the theoretical curves. The normal observers' data was positioned on the intensity axis using the product of the corneal intensity and the estimates of attenuation parameter nd derived previously for each observer. The patients' data were placed using their corneal intensities multiplied by the median value for the $n d_{1.125}$ obtained previously for the normals, since this model assumed that the ocular and receptor factors were normal.

Three theoretical curves are presented to illustrate three cases with various numbers of photoreceptors missing. The theoretical curves each asymptote at $<P(\operatorname{yes} \mid x)=1.0$ for high stimulus intensities. This is because when $m=5, \Pi(x)$, the probability of not activating a cone, quickly approaches zero as intensity increases. For example, $\Pi(10)=0.029$, and $\Pi(16) \approx 0$. But for the two exemplar patients' data, the intensities for seeing are $50<x<300$. Thus, if $m$ remains in the normal range, $\Pi(x)$ must be approx. 0 across the entire range of intensities actually shown to the patients. When $\Pi(x)=0$, equation (4) reduces to

$$
P(\text { yes } \mid x)=1 \quad(1-r / S)^{r} .
$$

Because $r$ and $S$ are constants, $P($ yes $\mid x)$ is a horizontal line, sketching out an asymptotic frequency-of-seeing at $<P($ yes $\mid x)=1.0$ no matter how bright the stimulus. In other words, given the high stimulus intensity to which these patients respond, if the test illuminated a normallyresponding receptor, that receptor would nearly certainly be activated, and the patient would see the flash. Thus for the patients, according to model 1 , there should be no dependence on the intensity of the flash for the range over which they saw the flashes. As Fig. 7 illustrates, this was patently not the case, and therefore the simple photoreceptors-missing model must be rejected.

However, the high intensities required by patients present a further confounding factor in interpreting Fig. 7. The three theoretical curves demonstrate that the asymptote is field size dependent. These three cases represent a constant proportion of detectors present $(16.7 \%)$, but the absolute number of detectors present $(r)$ increases with field size. Since $r$ acts as the exponent in the asymptotic expression (5), the asymptote approaches $P($ yes $\mid x)=1.0$ as $r$ becomes large. Thus for $r=1$, the detection curve asymptotes at $P($ yes $\mid x)=$ 0.167 . For $r=7, \quad P($ yes $\mid x) \rightarrow 0.730$; for $r=22$, $P($ yes $\mid x) \rightarrow 0.98$. The latter two examples are critical considering the viewing conditions of the Stargardt's observers, hecause they needed approx. $1.5 \mathrm{lng}$ more light than the normals. Consequently, their retinal image size is larger than that of the normal observers (Fig. 3). If, as is assumed in model 1 , the detectors respond normally to light, then the width of the patients' retinal light distribution must be defined as the width at which 
A

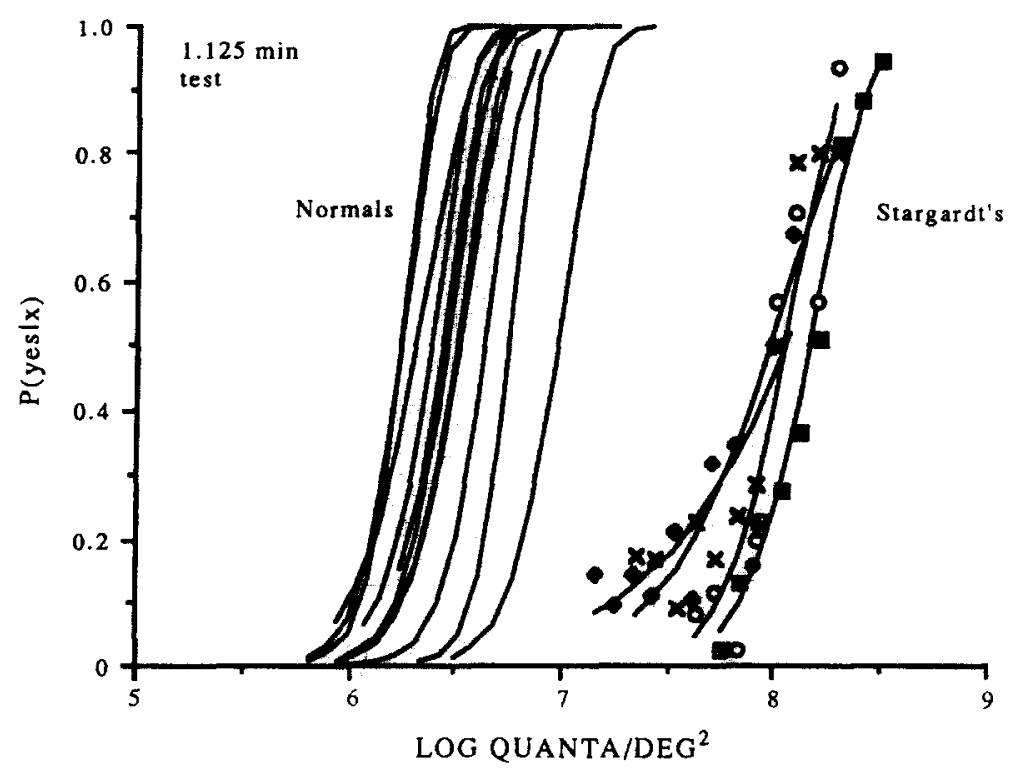

B

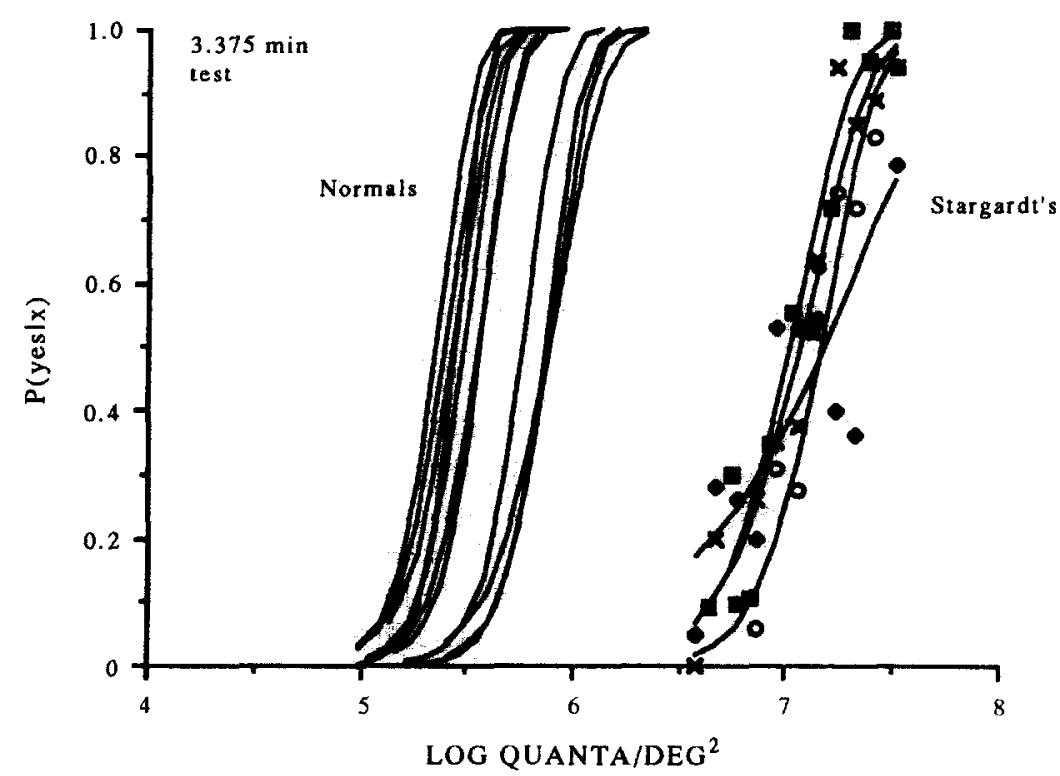

FIGURE S. Comparison of frequency-of-seeing data of patients and of normal observers. Normal observers are represented by their fitted curves. Stargardt's data are fit with curves to differentiate individual observers. (A) 1.125 min arc test field; (B) $3.375 \mathrm{~min}$ arc test field.

the intensity is equivalent to that of the normal distribution at half-height. Thus the $1.125 \mathrm{~min}$ arc test has an effective retinal size approximately equal to that of the $3.375 \mathrm{~min}$ arc test for the normals, while the patients' $3.375 \mathrm{~min}$ arc test is approx. $6 \mathrm{~min}$ arc in diameter. Since the absolute value of $r$ likely increases as a larger retinal area is illuminated, this forces the asymptote toward $P($ yes $\mid x)=1.0$ for large fields, even if $(r / S)$ is small. Thus the bright intensities required by these patients may preclude detecting the asymptote.

Model 2-increased number of effective quanta $\mathrm{m}$ needed for activation. An increase in the value of $m$ large enough to explain the great difference in sensitivity between the normal and patient populations would indicate considerable photoreceptor pathology and would implicate major changes in the transduction mechanism or deficiencies of critical substrates for trans- 
duction and activation. Changes of this type have been suggested by differences in the level and activity of the cyclic GMP-phosphodiesterase complex (cGMP-PDE) seen in the degeneraling photoreceptors of the autosomal recessive $r d$ mouse (Farber \& Shuster, 1985). Cyclic GMP is the internal messenger of phototransduction (cf. Pugh \& Altman, 1988), but at high levels it appears to be toxic to the photoreceptor (Farber \& Shuster, 1985). In the $r d$ mouse, the level of cGMP rises above normal due to reduced hydrolytic activity. While there is some hydrolysis of cGMP in response to light in these photoreceptors (and a measurablc ERG a-wave), the concentration of CGMP remains at much higher lcvels than observed in normal photoreceptors (Farber \& Shuster, 1985). Thus, before resulting in the death of the photoreceptor, this mutation results in a condition of defective transduction because light is less effective in changing the level of cGMP in the receptor cells. More absorbed (and therefore incident) quanta are required to activate the receptor, which translates as an increase in the parameter $m$ in the models examined here.
Figure $8(\mathrm{~A})$ illustrates the detection functions calculated with equation (1) for the condition of photoreceptors requiring extra quanta to be activated, i.e. for $m>5$. Figure $8(\mathrm{~A})$ shows the case of $m=50$ for three field sizes, reflected by the different values of $N$, assuming that no receptors are missing $(r=N=S)$. Note that high value of $m$ shifts the curves to an intensity range considerably higher than that required by normal observers. The curves are very steep and go from nonseeing to fully-seeing $(P($ yes $\mid x) \approx 0$ to $P($ yes $\mid x) \approx 1.0)$ over a narrow intensity range of approx. $0.1 \mathrm{log}$. Further, the number of detectors $(N)$ illuminated makes very little difference in the shape or position of the curve. These theoretical curves are far steeper even than the data of BS, who had the steepest detection function of the Stargardt's patient population. Observer BS required a range of approx. $0.6 \mathrm{log}$ units intensity to go from $P($ yes $\mid x) \approx 0$ to $P($ yes $\mid x)$ near 1.0 .

Although from these preliminary considerations, model 2 seemed not to be very useful, we tested it more formally. The effect of a high $m$ was evaluated by
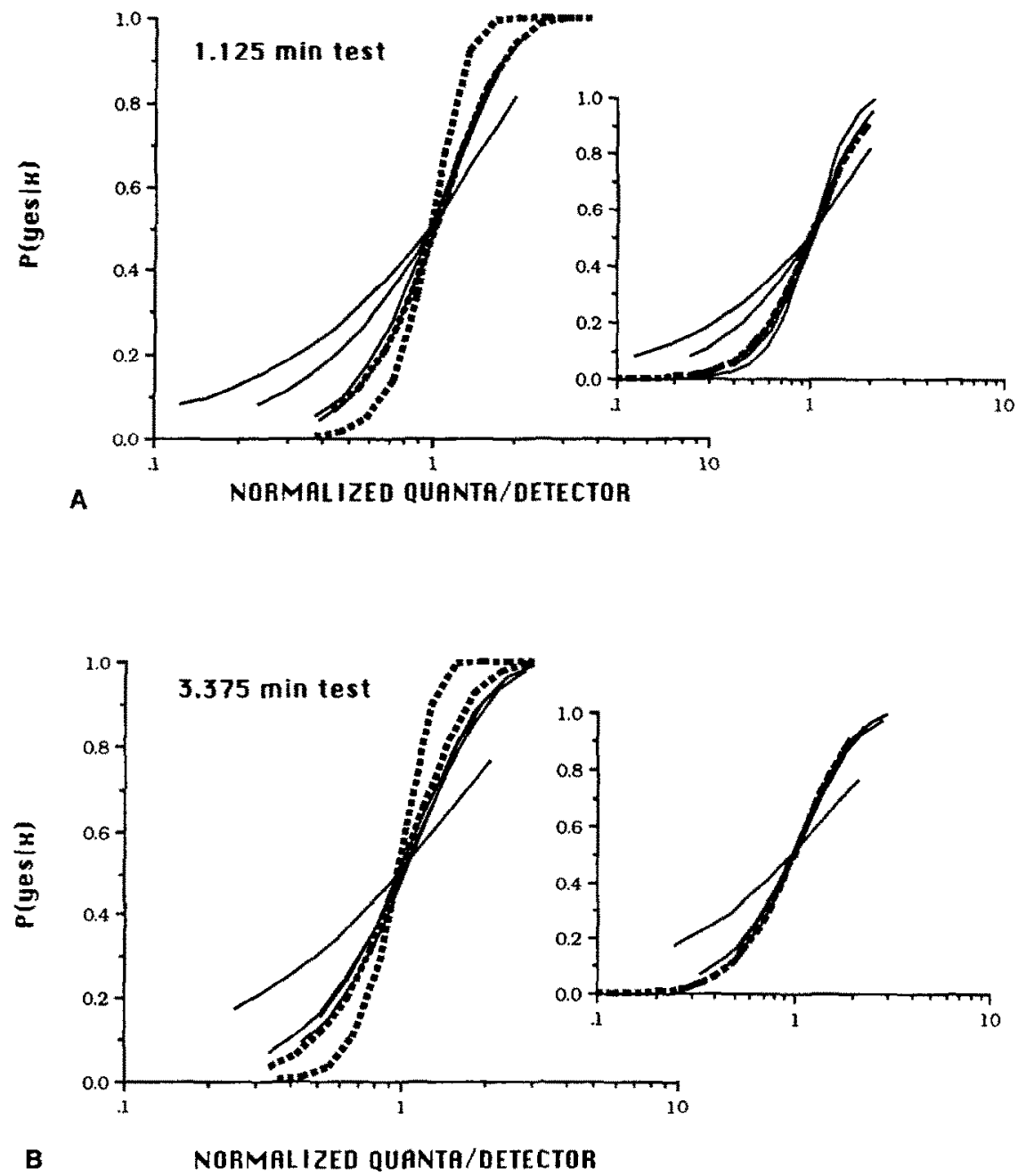

FIGURE 6. Comparison of shapes of four Stargardt's patients' frequency-of-seeing curves to the envelope of normal observers' functions. Frequency-of-seting curves for each observer are normalized at $P(x)=0.50$ threshold intensity to facilitate comparison of the slopes of the detection functions. The dotted lines show the envelope of the normals data defined by their minimally and maximally-sloped curves. For both of the test field sizes [(A) $1.125 \mathrm{~min}$ arc; (B) 3.375 min arc)], all of the patients" data are of shallower slope than the shallowest function of the normal observers. Insets show canonical frequency-of-seeing function (dotted curve) used to fit the parameter nd compared to patients' functions under each test condition. 


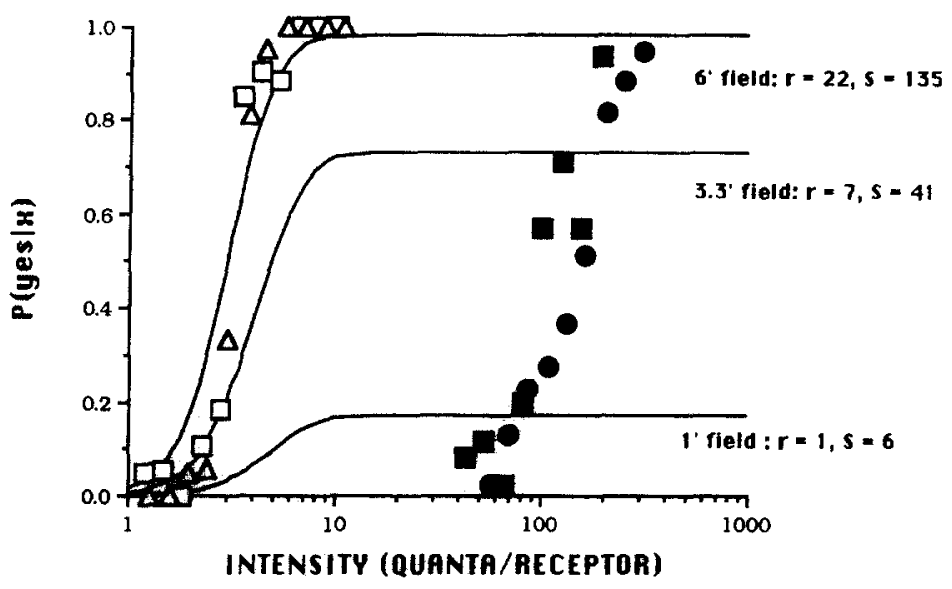

FIGURE 7. Model 1: reduced foveal cone number. Solid curves show theoretical detection functions corresponding to a loss of $83 \%$ of the photoreceptors for different test sizes. Parameters $r$ and $S$ are from equation (4). Open symbols show data of two normal observers (JJ, triangle; JC, square). Solid symbols show data of two Stargardt's observers (BS, circle; AW, square) for comparison.

estimating parameters $m$ and $N$ for the patients using equation (2). Retinal intensities $(x)$ were set by multiplying corneal intensities for each patient by the normal observers' median nd factor for the corresponding condition, under the assumptions that the ocular screening factors were the same as for normal observers and that, even though the higher intensities would spread light over a larger region, the high $m$ sharply limited the effective optical spread due to the probabilistic argument presented above for multiple quantal hits.

The resulting estimates of $m$ were generally quite high (e.g. median $m_{1.125}=32.09$ ) reflecting that higher values of $m$ were needed to shift the range over which $\Pi(x)$ showed intensity sensitivity to match the range of intensities over which the patients responded. Conversely, $N$ was very low, on the order of a few hundredths (e.g. median $N_{1.125}=0.03$ ), ostensibly to compensate for the steepness of the high $m$ fits. Although the high $m$ and low $N$ accurately set the detection thresholds to the higher intensities required by the patients, the fits were still poor in that $P($ yes $\mid x)$ asymptoted far below the experimental levels actually reached by the patients.

Further, combining a high $m$ with a photoreceptor loss of $r=1$ out of $S=6$ in equation (4) results in theoretical detection functions [Fig. 8(B)] which both asymptote and are far steeper than any observer's data. Thus model 2 did not fit the Stargardt's data, and it appeared unlikely that a change in the transduction capacity of the photoreceptors was responsible for the change in the location and shape of the detection functions shown by these patients.

Model 3-reduced quantum catch and missing photoreceptors. A third possibility for the decrease in patients' sensitivity is the presence of processes which act to screen out a higher percentage of incident quanta than in normals, analogous to the interposition of a neutral density filter. One major process affecting such a change could be a reduction in optical density leading to reduced quantum-catching ability. Because optical density is in part a function of light-path length, optical density could be reduced through the shortening of photoreceptor outer segments, as has been found histologically for retinitis pigmentosa (RP) (Kolb \& Gouras, 1974; Szamier, Berson, Klein \& Meyers, 1979). Van Meel and van Norren (1986) showed with fundus reflection densitometry that the two-way densities in the fovea of Stargardt's patients were $0.03-0.20$ that of normals. This corresponds with conclusions that reduced pigment density could account for the pseudoprotanomalous shift in color matches of Stargardt's and RP patients (Keunen, Smith, Pokorny \& Mets, 1991; Pokorny et al., 1980; Young \& Fishman, 1980, 1982). Moreover, in RP, elevation of psychophysical thresholds correlated with the reduction in densitometrically-measured pigment density (Ripps, Brin \& Weale, 1978; Van Meel \& Van Norren, 1983). If this correspondence held for Stargardt's patients as well, then at the low end of the absorption range reported by Van Meel and Van Norren, reduced pigment density would account for a $1.5 \log$ difference in effective quantum catch between the patients and the normals.

An additional process acting to reduce quantum catch would be a loss of sensitivity due to the directional sensitivity (Stiles-Crawford Effect I) of the photoreceptors. In some Stargardt's patients, the cones show a loss of directional sensitivity which Pokorny et al. (1980) have taken as evidence that disorganization among the foveal cones misaligns the optical axes of these photoreceptors away from the pupil. Such a misalignment would decrease the quantum catch of these cones and therefore decrease the measured sensitivity if many photoreceptors are not facing the optimal axis. Empirically, however, cone threshold sensitivities have not previously been measured for Stargardt's patients. As a contrary example, while some RP patients show reduced directional sensitivity, there is no correlation between the change in directional selectivity and reduction in cone sensitivity (Birch, Sandberg \& Berson, 1982). 
To evaluate model 3 , we first modeled a change in the effective retinal illuminance using approach 2 from above, fitting the patients' data with equation (3) and a template curve to estimate the $n d$ parameter. The values $m=6$ (as in normals), and $N=0.25$ produced a curve which reflected the shape of the patients' frequency-ofseeing curves (inset, Fig. 6) for both the small and larger fields. The best-fitting $n d$ values were on the order of 1.0-1.3 log units less than those for the normals (compare Tables 3 and 4), and produced the greater attenuation of corneal intensity required to compensate for the higher intensities at which the patients responded. This higher range over which $\Pi(x)$ remained sensitive to intensity reflects the reduced effective retinal illumination for the Stargardt's patients according to model 3 .

Once $n d$ had been obtained for the patients, a value of $r$ could be estimated by fitting their data with equation (4). We multiplied the patients' nd values and the

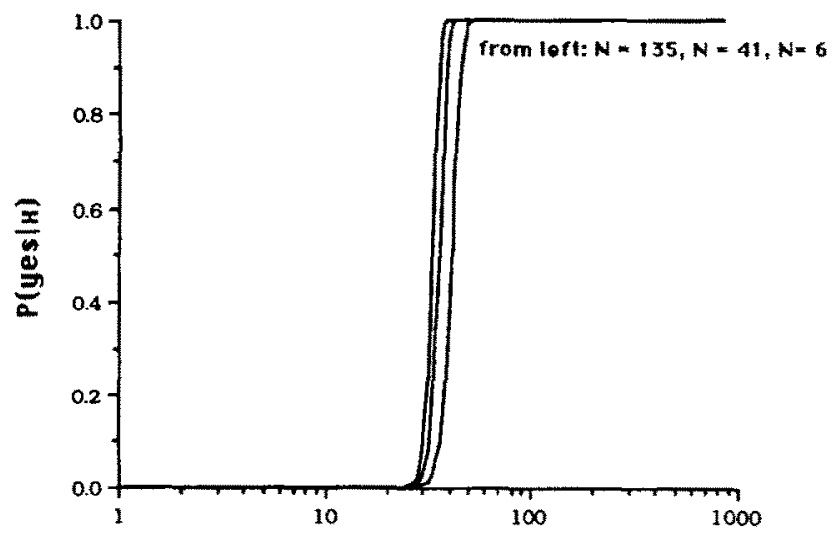

ต

INTENSITY (QUANTA/RECEPTOR)

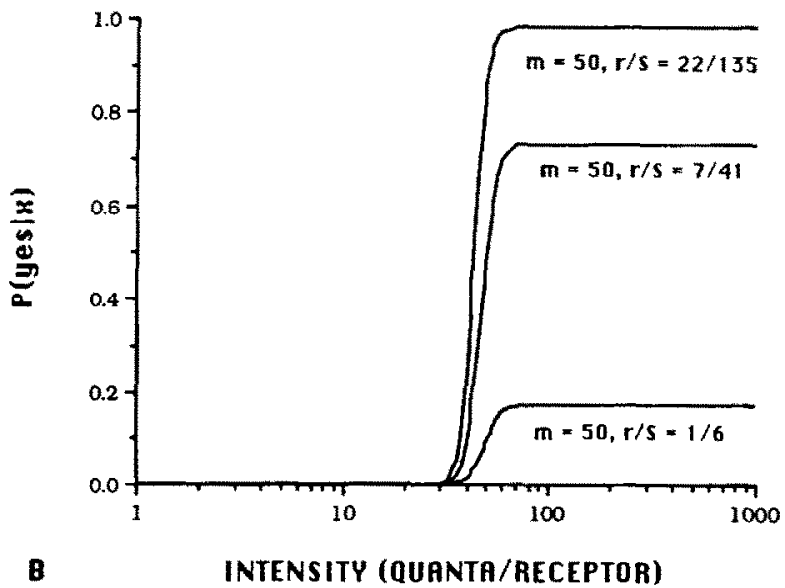

FIGURE 8. Model 2; elevated number of quanta $m$ needed to achieve activation. (A) Curves calculated with $m=50$ and different numbers of photoreceptors equivalent to different field sizes in a fully populated retina. (B) Theoretical functions showing the combined effect of $m=50$ and a loss of $83 \%$ of the photoreceptors for three different field sizes. threshold corneal intensities of the test stimuli to set the values for intensity $x$ as had been done above with the normal population (Table 4, columns 2,3,4 and 5,6,7), while setting $S$ (number of available slots) $=41$ for the small test and $N=135$ for the large test, reflecting the optical spread of the test stimuli at the higher intensities needed by the patients consistent with holding $m=6$. The values of $r$ obtained with these fits indicated a loss of $85-92 \%$ of the photoreceptors in the central fovea for this patient population (Table 4). As seen in Fig. 9, these were not perfect fits. In particular, the model fit the $P($ yes $\mid x)$ values at the lower intensities, but the curves still tended to asymptote below the level of detection attained by the patients. This may be because the model does not take into account the continuous change in field size with intensity, which, as was explained above, tends to push the asymptote toward 1.0. A higher value for $m$ would also raise the asymptote, but this would result in a steeper curve which would not improve the fit. Of the models considered, model 3 provided the most satisfactory fit to the experimental data because it accounted for both the shift in absolute threshold and the shallower slopes of the frequency-of-seeing functions of the patient population.

\section{SUMMARY AND CONCLUSIONS}

In a population of normal observers, we obtained estimates of $m$, the quantal requisite for activation of a single foveal detector element, and $N$, the number of photoreceptors illuminated by a test flash, by estimating an ocular screening parameter $n d$ which scaled intensity at the cornea to retinal intensity in terms of effective quanta/detector and then fitting the data to the model of foveal detection presented by Cicerone and Nerger (1989a). The values obtained for $m$ by fitting the data from both test field sizes agreed with previous estimates (Marriott, 1963; Cicerone \& Nerger, 1989a; Vimal et al., 1989; Wesner et al., 1991). The values of $N$ agreed with expectations based on retinal anatomy and our calculations of retinal image size for the small test field but were below expectations for the larger test possibly due to as yet undetermined pooling of detection signals, particularly under dark viewing conditions. The size of the foveal summation zone has been estimated to be 2.4 $5 \mathrm{~min}$ arc in diameter (Westheimer, 1967; Inui, Mimura \& Kani, 1981; Glezer, 1965; Toct \& Levi, 1991). While the notion of foveal summation calls into question the assumption of cone independence, ideal observer analyses and the physiology and psychophysics cited earlier support the notion of "private line", single-conecenter receptive fields, suggesting that such summation is due to pre-neural, i.e. optical, factors (Davila \& Geisler, 1991; Geisler \& Bennett, 1987). This makes the method of stimulus presentation critical, since even with an optical system, the tiny stimuli necessary for this work are blurred by the eye's optics. Stimuli which are freeviewed through a dilated pupil, for example, would produce retinal images far larger than their geometric image sizes. 
TABLE 4. Stardardt's patients: corneal thresholds, parameter $n d$, and threshold effective quanta/"receptor site" for each Stardardt's patient for model 3, and estimates of $r$ and the ratio $r / S$ of the estimated number of remaining photoreceptors to the number of photoreceptor slots $(S)$ given the increased image sizes due

\begin{tabular}{|c|c|c|c|c|c|c|c|c|}
\hline Name & $\begin{array}{c}\text { Corneal log } \\
\text { quanta at } \\
\text { threshold } \\
1.125 \mathrm{~min} \\
\text { arc test }\end{array}$ & $\begin{array}{l}n d_{1,125} \\
\times 10^{-4}\end{array}$ & $\begin{array}{l}\text { Effective } \\
\text { quanta/ } \\
\text { receptor } \\
1.125 \mathrm{~min} \\
\text { arc test }\end{array}$ & $\begin{array}{c}\text { Corneal log } \\
\text { quanta at } \\
\text { threshold } \\
3.375 \text { min } \\
\text { arc test }\end{array}$ & $\begin{array}{l}n d_{3,3,5} \\
\times 10^{-4}\end{array}$ & $\begin{array}{l}\text { Effective } \\
\text { quanta/ } \\
\text { receptor } \\
3.375 \text { min } \\
\text { arc test }\end{array}$ & $\begin{array}{c}r_{1125} \\
r / S \\
(S=41)\end{array}$ & $\begin{array}{c}r_{3375} \\
r / S \\
(S=135)\end{array}$ \\
\hline AP & 4.502 & 4.77 & 15.15 & .576 & 2.98 & 11.23 & $\begin{array}{l}4.96 \\
0.12\end{array}$ & $\begin{array}{c}11.05 \\
0.082\end{array}$ \\
\hline AW & 4.481 & 3.25 & 9.84 & 4.541 & 2.95 & 10.25 & $\begin{array}{l}5.54 \\
0.135\end{array}$ & $\begin{array}{c}11.66 \\
0.086\end{array}$ \\
\hline BS & 4.611 & 2.51 & 10.25 & 4.391 & 4.02 & 9.891 & $\begin{array}{l}5.97 \\
0.15\end{array}$ & $\begin{array}{c}11.98 \\
0.089\end{array}$ \\
\hline RM & 4.421 & 4.10 & 10.81 & 4.451 & 3.60 & 10.17 & $\begin{array}{l}5.77 \\
0.14\end{array}$ & $\begin{array}{c}11.88 \\
0.088\end{array}$ \\
\hline
\end{tabular}

For a sample of patients with Stargardt's macular dystrophy, foveal absolute thresholds were elevated approx. $1.5 \mathrm{log}$ units from the normal population. The frequency-of-seeing functions of these patients had somewhat shallower slope than the corresponding functions from the normal observers. While the decrease in slope may have resulted from eccentric fixation which would have resulted in the recruitment of fewer. larger detection units, we consider this unlikely given our alignment strategy and that rod intrusion would likely have resulted in a decrease in threshold, since rod sensitivity at the test wavelength of $580 \mathrm{~nm}$ is $1.5 \mathrm{log}$ greater than cone sensitivity (Wyzecki \& Stiles, 1982).

Some previous studies have suggested that foveal thresholds are elevated in patients with photoreceptor dystrophies due to reduced photoreceptor density (Sandberg \& Berson, 1983; Greenstein, Hood, Seigel \& Carr, 1984; Alexander, Derlacki, Fishman \& Peachey, 1991) while others have suggested that a reduction in the

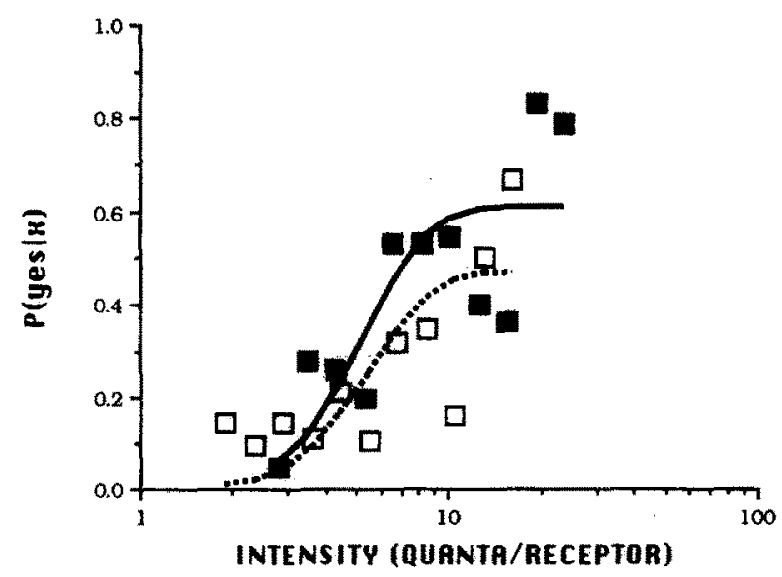

FIGURE 9. Model 3: effect of reduced quantal absorption combined with foveal cone losses. This is illustrated by fits to data of patient AP. Data were fit by estimating $r$, the number of remaining receptors, using equation (4), setting $N=41$ and 135 for the small and large fields respectively, $m=6$, and $x=n d * X$. Solid curve and solid symbols are for large test. Broken curve and open symbols are for small test. effective optical density of the photoreceptors is also a factor (Young \& Fishman, 1982). Our estimate of an approx. $1 \log$ unit decrease in foveal cone photoreceptor density in Stargardt's patients (Table 4) corresponds approximately with the increase in foveal absolute threshold, but our model 1 shows that loss of photoreceptors alone cannot account for such a shift in threshold when the photoreceptors are assumed to be independent foveal detectors.

The modeling also suggested that an increase in the quantal requisite for activation (model 2 ) is inadequate to explain both the patients' shift in threshold intensity and the decrease in slope of their frequency-of-seeing functions. Model 3 coupled a decrease in quantal absorbance with a loss of photoreceptors, and this model accounted better than the other two for both the shift in threshold and the shallowness of the patients' detection functions. Complications in modeling introduced by the interaction of intensity and retinal image size for the tiny stimuli used in these experiments may account for the disparities in asymptotes at high intensities between this final model 3 and the patients' data. We do note, however, that the loss of approx. $90 \%$ of the photoreceptors in our patient sample estimated by model 3 is of the magnitude which was necessary to bring about changes in visual acuity according to our earlier simulation of macular degeneration (Geller et al., 1992).

How well does this reflect anatomical reality? Stargardt's disease leads to profound macular photoreceptor loss, and there is some evidence of cone outer segment shortening (Eagle et al,, 1984; Järveläinen \& Milam, unpublished data), yet visual acuity better than $20 / 40$ can persist into the fifth decade of life (Fishman et al., 1987). While different from the human condition, psychophysical and histopathological studies in rats and mice with light-induced or inherited outer retinal degeneration conclude that these animals can perform light and pattern discrimination with very few or, at best. severely impaired photoreceptors (Nagy \& Misanin, 1970; Anderson \& O'Steen, 1972; LaVail, Sidman, Rausin \& Sidman, 1974). Our results are further confirmation that large numbers of good cones are not an 
absolute requisite for detection and discrimination (Geller et al., 1992).

\section{REFERENCES}

Alexander, K. R., Derlacki, D. J., Fishman, G. A. \& Peachey, N. S. (1991). Acuity-luminance and foveal increment threshold functions in retinitis pigmentosa. Investigative Ophthalmology and Visual Science, 32, 1446-1454.

Anderson, K. V. \& O'Steen, W. K. (1972). Black-white and pattern discrimination in rats without photoreceptors. Experimental Neurology, 34, 446-454.

Banks, M. S., Geisler, W. S. \& Bennett, P. J. (1987). The physical limits of grating visibility. Vision Research, 11, 1915-1924.

Baumgardt, E. (1972). Threshold quantal problems. In Jameson, D. \& Hurvich, L. M. (Eds), Handbook of sensory physiology (Vol. VII/4). New York: Springer.

Birch, D. G., Sandberg, M. A. \& Berson, E. L. (1982). The StilesCrawford effect in retinitis pigmentosa. Investigative Ophthalmology and Visual Science, 22, 157-164.

Birch, J., Chisholm. I. A., Kinncar, P., Marré, M., Pinckers, J. L. G., Pokorny, J., Smith, V. C. \& Verriest, G. (1979). Acquired color vision defects. In Pokorny, J., Smith V. C., Verriest, G \& Pinckers A. J. L. G., (Eds), Congenital and acquired color vision defects. New York: Grune \& Stratton.

Bird, A. C. \& Marshall, J. (1982). Retinal receptor disorders without known metabolic abnormalities. In Garner \& Klintworth (Eds). Pathobiology of ocular disease, part B. New York: Dekker.

Bowmaker, J. K. (1981). Visual pigments and colour vision in man and monkeys. Journal of the Royal Society of Medicine, 74, 348-356.

Boynton, R. (1972). Discrimination of homogeneous double pulses of light. In Jameson, D. \& Hurvich, L. M. (Eds), Handbook of sensory Physiology (Vol. VII/4). New York: Springer.

Campbell, F. W. \& Gubisch, R. W. (1966). Optical quality of the human eye. Journal of Physiology, 186, 558-578.

Cicerone, $\mathrm{C}$ \& Nerger, J. ( $989 \mathrm{a}$ ). The relative numbers of long-wavelength-sensitive and middle-wavelength-sensitive cones in the human fovea centralis. Vision Reseurch, 29, 115-128.

Cicerone, C. \& Nerger, J. (1989b). The density of cones in the fovea centralis of the human dichromat. Vision Research, 29, 1587-1595.

Davila, K. D. \& Geisler, W. S. (1991). The relative contributions of preneural and neural factors to areal summation in the fovea. Vision Research, 31, 1369-1380.

DeMonasterio, F. M. \& Gouras, P. (1975). Functional properties of ganglion cells of the rhesus monkey retina. Journal of Physiology, $251,167-195$.

Derrington, A. M. \& Lennie, P. (1984). Spatial and temporal contrast sensitivities of neurones in lateral geniculate nucleus of macaque. Journal of Physiology, 357, 219-240

Eagle, R. C., Lucier, A. C., Bernardino, V. B. \& Yanoff, M. (1980) Retinal pigment epithelial abnormalities in fundus flavimaculatis. Ophthalmology, 87, 1189-1200.

Farber, D. \& Shuster, T. A. (1985). A proposed sequence of events leading to photoreceptor degeneration in the $r d$ mouse retina. In LaVail, M. M., Hollyfield, J. G. \& Anderson, R. E. (Eds), Retina degeneration: Experimental and clinical studies. New York: Liss.

Fishman, G. A., Farber, M., Patel, B. S. \& Derlacki, D. J. (1987) Visual acuity loss in patients with Stargardt's macular dystrophy. Ophthalmology, 94, 809-814

Geller, A. M.. Sieving. P. A. \& Green, D. G. (1992). Effect on grating identification of sampling with degenerate arrays. Journal of the Optical Society of America, A 9, 472-477.

Glezer, V. D. (1965). The receptive fields of the retina. Vision Research 5, $497-525$

Green, D. G. (1970). Regional variations in the visual acuity for interference fringes on the retina. Journal of Physiology, 207. $351 \cdots 356$.

Green, D. M. \& Swets, J. A. (1966). Signal detection theory and psychophysics. New York: Wiley.

Greenstein, V. C.. Hood, D. C.., Seigel, I. M. \& Carr, R. E. (1984) Retinitis pigmentosa: A psychophysical test of explanations for early foveal sensitivity loss. Investigative Ophthalmology and Visual Science, 25, 118-120

Gubisch, R. W. (1967). Optical performance of the human eye. Journal of the Optical Society of America, 57, 407-415.

Hecht, E. \& Zajac, A. (1979). Optics. Reading, Mass.: AddisonWesley.

Hecht, S., Schlaer, S. \& Pirenne, M. (1942). Energy, quanta, and vision. Journal of General Physiology, 25, 819-840.

Hirsch, J. \& Curcio, C. (1989). The spatial resolution capacity of human foveal retina. Vision Research, 29, 1095-1101.

Hood, D. \& Finkelstein, M. A. (1988). Sensitivity to light. In Boff, K. R., Kauffman, L. \& Thomas, J. P. (Eds), Handbook of perception and human performance (Vol. 1). New York: Wiley.

Inui, T., Mimura, O. \& Kani, K. (1981). Retinal sensitivity and spatial sumation in the foveal and parafoveal regions. Journal of the Optical Society of America, 7I, 151-154.

Klien, B. A. \& Krill, A. E. (1967). Fundus flavimaculatis-clinical, functional, and histopathologic observations. American Journal of Ophthalmology, 64, 3-23.

Kolb, H. \& Gouras, P. (1974). Electron microscopic observations of human retinitis pigmentosa, dominantly inherited. Investigative Ophthalmology and Visual Science, 13, 487-498.

Keunen, J. E. E., Smith, V. C., Pokorny, J. \& Mets, M. B. (1991) Stiles-Crawford effect and color matching in Stargardt's disease American Journal of Ophthalmology. 112, 216-217.

Krauskopf, J. (1978). On identifying detectors. In Armington, J. C., Krauskopf, J. \& Wooten, B. R. (Eds). Visial psychophysics and physiology. New York: Academic Press.

Krauskopf, J. \& Srebo, R. (1965). Spectral sensitjvity of color mechanisms: Derivation from fluctuations of color appearance near threshold. Science, 150, 1477-1479.

LaVail, M. M., Sidman, M., Kausin, K. \& Sidman, K. L. (1974) Discrimination of light intensity by rats with inherited retinal degeneration. Vision Research, 14, 693 702.

Marriott. F. H. C. (1963). The foveal absolute visual threshold for short flashes and small fields. Journal of Physiology, I69, 416423

Nagy, Z. M. \& Misanin. J. F. (1970). Visual perception in the retina degenerate $\mathrm{C} 3 \mathrm{H}$ mouse. Journal of Comparative Physiology and Psychology, 72, 306-310.

Noble, K. G. \& Carr, R. E. (1979). Stargardt's disease and fundus flavimaculatis. Archives of Ophthalmology, 97, 12811285

Ogle, K. N. (1971). Optics. Springfield, Ill.: Charles C. Thomas.

Pirenne, M. H. \& Marriott, F. H. C. (1955). Absolute threshold and frequency-of-secing curves. Journal of the Optical Society of America. 45, 909-912.

Pirenne, M. H. \& Marriott, F. H. C. (1959). The quantum theory of light and the psycho-physiology of vision. In Koch, $\mathrm{S}$. (Ed.), Psychology: A study of science (Vol. 1). New York McGraw-Hill

Pokorny, J., Smith, V. C. \& Ernest, J. T. (1980). Macular color vision defects: Specialized psychophysical testing in acquired and hereditary chorioretinal diseases. In Sokol, S. (Ed.). Electrophysiology and psychophysics: Their use in ophthalmic diagnosis, I.O.C. 20. Boston. Mass: Little Brown

Pugh, E. \& Altman, J. (1988). A role for calcium in adaptation. Nature, 34, 16-17

Ripps, H., Brin, K. P. \& Weale, R. A. (1978). Rhodopsin and visual threshold in retinitis pigmentosa. Investigative Ophthalmology and Visual Science, 17, 735-745.

Sandberg, M. A. \& Berson, E. L. (1983). Visual acuity and cone spatial density in retinitis pigmentosa. Imestigatime Ophthalmology and Visual Science, 24, 1511-1513.

Szamier, R. B., Berson, E. L., Klein, R. \& Meyers, S. (1979) Sex-linked retinitis pigmentosa: Ultrastructure of photoreceptors and pigment epithelium. Investigative Ophthalmology and Visual Science, $18,145-160$

Thibos, L., Cheney, F. E. \& Walsh, D. J. (1987). Retinal limits to the detection and resolution of gratings. Journal of the Optical Society of America, A, 4, 1524-1529.

Toet, A. \& Levi, D. M. (1991). The two-dimensional shape of spatial interaction zones in the parafovea. Vision Research, 32, 1349-1357. 
Van Meel, G. J. \& van Norren, D. (1983). Foveal densitometry in retinitis pigmentosa. Investigative Ophthalmology and Visual Science, 24, 1123-1130.

Van Meel, G. J. \& van Norren, D. (1986). Foveal densitometry as a diagnostic technique in Stargardt's disease. American Journal of Ophthalmology, 102, 353-362.

Vimal, R. L. P., Pokorny, J., Smith, V. C. \& Shevell, S. K. (1989). Foveal cone thresholds. Vision Research, 29, 61-78.

Wässle, H., Grünert, U., Röhrenbeck, J. \& Boycott, B. (1989). Cortical magnification factor and the ganglion cell density of the primate retina. Nature, 341, 643-646.

Weleher, R. G. \& Fisner, A. (1988). Cone degeneration ("Bull's-eye" dystrophies) and color vision defects. In Newsome, D. A. (Ed.), Retinal dystrophies and degeneration. New York: Raven Press.

Wesner, M. F., Pokorny, J., Shevell, S. K. \& Smith, V. C. (1991). Foveal cone detection statistics in color-normals and dichromats. Vision Research, 31, 1021-1037.

Westheimer, G. (1967). Spatial interaction in human cone vision. Journal of Physiology, 190, 139-154.

Westheimer, G. (1986). The eye as an optical instrument. In Boff, K. R., Kauffman, L. \& Thomas, J. P. (Eds), Handbook of perception and human performance (Vol. 1). New York: Wilcy.

Wilkinson, L. (1989). SYSTAT: The system for statistics. Evanston, III.: SYSTAT,
Williams, D. R. (1990). The invisible photoreceptor mosiac. In $A d$ vances in photoreception, proceedings of a symposium on the frontiers of visual science. Washington, D. C.: National Academy Press.

Williams, D. R. \& Colleta, N. (1987). Cone spacing and the visual resolution limit. Journal of the Optical Society of America, A, 4, 1514-1522

Wilson, H. (1991). Model of peripheral and amblyopic hyperacuity. Vision Research, 31, 967-982.

Wyszecki, G. \& Stiles, W. S. (1982). Color science. New York: Wiley. Young, R. S. L. \& Fishman, F. L. (1980). Color matches of patients with retinitis pigmentosa. Investigative Ophthalmology and Visual Srience, 19, 967-972.

Young, R. S. L. \& Fishman, G. L. (1982). Sensitivity losses in a long wavelength sensitive mechanism of patients with retinitis pigmentosa. Vision Research, 22, 163-172.

Acknowledgements - This research was supported by the National Retinitis Pigmentosa Foundation, Inc., Baltimore, Md and by $\mathrm{Na}$ tional Institutes of Health T32-EY07022. We thank John Lee for his substantial contributions of time and energy, and Dan Green, Dan Weintraub, and Keith Smith for their valuable comments and suggestions. 